\title{
Survey of Barriers and Facilitators to Engagement in a Multidisciplinary Healthy Lifestyles Program for Children
}

\author{
Cervantée E.K. Wild, BHSc(Hons) ${ }^{1}$; Niamh A. O'Sullivan, MSc, RD ${ }^{1,2}$; Arier C. Lee, PhD ${ }^{3}$; \\ Tami L. Cave, PGDipPH ${ }^{1}$; Esther J. Willing, $\mathrm{PhD}^{4}$; Donna M. Cormack, $\mathrm{PhD}^{5}$; \\ Paul L. Hofman, FRACP ${ }^{1,6}$; Yvonne C. Anderson, PhD, FRACP ${ }^{1,2}$
}

\begin{abstract}
Objective: To understand facilitators and barriers to engagement in a multidisciplinary assessment and intervention program for children and adolescents with obesity, particularly for Māori, the Indigenous people of New Zealand.

Methods: Whānau Pakari participants and caregivers $(n=71,21 \%$ response rate) referred to the family-based healthy lifestyles program in Taranaki, New Zealand, were asked to participate in a confidential survey, which collected self-reported attendance levels and agreement with statements around service accessibility and appropriateness and open-text comments identifying barriers and facilitators to attendance.

Results: Self-reported attendance levels were higher when respondents reported sessions to be conveniently located $(P=.03)$ and lower when respondents considered other priorities as more important for their family $(P=.02)$. Māori more frequently reported that past experiences of health care influenced their decision to attend $(P=.03)$. Facilitators included perceived convenience of the program, parental motivation to improve child health, and ongoing support from the program.

Conclusions and Implications: Program convenience and parental and/or self-motivation to improve health were facilitators of attendance. Further research is required to understand the relationship between past experiences with health care and subsequent engagement with services.
\end{abstract}

Key Words: obesity, child, facilitators, barriers, retention (J Nutr Educ Behav. 2020; 52:528-534.)

Accepted October 20, 2019. Published online November 26, 2019.

\section{INTRODUCTION}

One of the key recommendations of the World Health Organization's Report of the Commission on Ending Childhood Obesity is to "provide family-based, multicomponent lifestyle weight-management services for children and young people who are obese." ${ }^{1}$ Improving access to nutrition and physical activity programs for families in Aotearoa, also known as New Zealand, is a targeted initiative of the current national Childhood Obesity Strategy. ${ }^{2}$ Childhood obesity now affects $11 \%$ of children aged 2-14 years in New Zealand. ${ }^{3}$ New Zealand children and adolescents with obesity have a concerning prevalence of weight-related comorbidities, suboptimal eating behaviors, low physical activity, and psychological difficulties, irrespective of ethnicity. ${ }^{4-7}$ However, Mãori, New Zealand's Indigenous population, are 1.6 times more likely to experience obesity than their

\footnotetext{
${ }^{1}$ Liggins Institute, University of Auckland, Auckland, New Zealand

${ }^{2}$ Department of Pediatrics, Taranaki District Health Board, New Plymouth, New Zealand

${ }^{3}$ Section of Epidemiology and Biostatistics, University of Auckland, Auckland, New Zealand

${ }^{4}$ Kōhatu-Centre for Hauora Māori, University of Otago, Dunedin, New Zealand

${ }^{5}$ Te Kupenga Hauora Māori, University of Auckland, Auckland, New Zealand

${ }^{6}$ Starship Children's Health, Auckland District Health Board, Auckland, New Zealand

Conflict of Interest Disclosure: The authors have not stated any conflicts of interest.

Address for correspondence: Cervantée E. K. Wild, BHSc(Hons), Liggins Institute, University of Auckland, 85 Park Rd, Auckland 1023, New Zealand;

E-mail: cervantee.wild@auckland.ac.nz

(C) 2019 The Authors. Published by Elsevier Inc. on behalf of Society for Nutrition Education and Behavior. This is an open access article under the CC BY-NC-ND license. (http:// creativecommons.org/licenses/by-nc-nd/4.0/)

https://doi.org/10.1016/j.jneb.2019.10.010
}

non-Māori counterparts. ${ }^{3}$ In addition, children living in households in the most socioeconomically deprived areas are 2 times more likely to have obesity than children living in the least deprived areas. $^{3}$ Therefore, multidisciplinary interventions must be able to engage with these groups to produce equitable outcomes.

The success of childhood obesity management programs depends on both initial recruitment and ongoing retention. ${ }^{8}$ Ethnicity and socioeconomic status are associated with adherence within pediatric weightmanagement programs-a systematic review highlighted that black participants showed higher dropout rates in weight-management interventions than white participants, and low family income was associated with lower attendance in weight-management programs in the US. ${ }^{9}$ Previous studies have identified that specific factors may enable (described as facilitators) or inhibit (described as barriers) engagement in terms of recruitment and retention. ${ }^{10,11}$ These may be internal to 
the service, such as a family-focused program design and effective program staff, or external to the service, such as personal logistics, time pressures, and parental acknowledgment of weight. ${ }^{10,11}$ Indigenous groups, such as Māori, face additional barriers to health care access and use due to significant socioeconomic disadvantage, racial discrimination, and social marginalization, ${ }^{12}$ largely due to the lasting effects of colonization. ${ }^{13}$ However, previous studies have not specifically explored barriers for Indigenous groups in accessing community-based healthy lifestyle programs for children and their families. ${ }^{10}$ Therefore, it is necessary to understand which factors act as barriers and facilitators to attendance, retention, and engagement in weight-management programs, especially for groups most likely to experience obesity. ${ }^{10}$

Whānau Pakari is a multidisciplinary assessment and intervention program for children and adolescents based in Taranaki, a semirural region of New Zealand. ${ }^{14}$ The family-centered service assesses individuals in their homes, essentially "demedicalizing" care by removing pediatrician and dietitian hospital appointments. Whanau Pakari is a communitybased intervention program replacing the conventional secondary care clinical service and is unique because it incorporates a home-based medical assessment and intervention into 1 program. Weekly sessions of approximately 1-hour duration took place at community sporting venues and incorporated dietary sessions, including the concept of healthy food, portion size, cooking sessions, virtual supermarket tours; family physical activity sessions, including a variety of sports and games to find participants' interests; and psychology sessions, covering topics such as self-esteem and how to make healthy lifestyle changes. ${ }^{14}$ Participants and accompanying family members signed a commitment contract, in which it was explained that participants were expected to attend $\geq 70 \%$ of program sessions. ${ }^{14,15}$ The program included a 6- and 12-month option, with further follow-up. ${ }^{16}$ The service was established in 2012, and eligibility criteria are children aged $4-16$ years, assessed as either falling in the obese (body mass index $[\mathrm{BMI}] \geq 98$ th percentile), or overweight (BMI >91st percentile) categories with associated weightrelated comorbidities, according to UK Cole cutoffs for BMI based on age and gender. ${ }^{14,17}$

A randomized clinical trial embedded within the healthy lifestyles program showed increased reach with equal engagement of Māori and New Zealand European participants (comprising $47 \%$ and $43 \%$ of trial participants, respectively) and with $29 \%$ of participants from the most deprived quintile of household deprivation compared with $15 \%$ of the overall population. ${ }^{7,18}$ Overall, all participants, irrespective of being in the high-intensity intervention or low-intensity control group, achieved a BMI SD score reduction of 0.1 at 12 months. ${ }^{16}$ However, when participants attended $\geq 70 \%$ of intense intervention sessions (the number recommended before onset of the study), the change in BMI SD score was -0.22 compared with -0.04 for those attending $<70 \%$ $(P=.04) .{ }^{16}$ Improvements were also seen in health-related quality of life and cardiovascular fitness in both the intervention and control groups. ${ }^{16}$

The aim of this study was to assess the barriers and facilitators to attendance, retention, and engagement in Whānau Pakari, particularly for Mãori, by surveying past participants of the program as part of ongoing program efforts to address equity and retention. Second, to examine the association between ethnicity and perceived accessibility and acceptability of the program. It was anticipated that program factors such as location and timing of assessments and sessions would impact participant engagement. This survey was an initial process preceding indepth interviews with families.

\section{METHODS}

Ethical approval for the Whanau Pakari Barriers and Facilitators study was granted by the Central Health and Disability Ethics Committee (New Zealand) (17/CEN/158/AM01). Electronic written consents were obtained from all participants.

\section{Participants}

Participants were from a convenience sample of past Whānau Pakari service users who had a current contact phone number on record. Inclusion criteria were parents and caregivers (or children if over 11 years of age) from the original randomized clinical trial and post-trial service users and those who were offered a referral to the service but declined further input, from establishment of the service in January 2012 to January 2017 (program content and delivery did not change post-trial). Participants who repeated the program twice back-to-back were excluded because of expected inaccuracies in attendance reporting.

\section{Data Collection}

Qualtrics software (Qualtrics, Provo, UT, 2018) was used to build the online survey, where written consent was obtained through clicking a button stating agreement with the consent statement. The survey development was informed by the theoretical framework of the broader study, which drew from Kaupapa Mãori theory ${ }^{19,20}$ and ecosocial theory. ${ }^{21}$ This guided the identification and development of survey questions to capture structural and organizational barriers and facilitators, rather than a narrow focus on characteristics of individuals or families. The survey questions gathered data about the variables that enabled participation and those factors, which deterred people from taking part. The questions were developed in consultation with a range of Māori and non-Māori researchers and stakeholders, including the Public Health Unit at Taranaki District Health Board, and were beta-tested to assess comprehension and face validity. Both the computer and mobile versions were verified for Web page responsiveness. The survey included both quantitative (demographics, yes or no questions, and Likert scales assessing agreement with statements) and qualitative (open-text comment) questions. As the survey was confidential, and the online version was anonymous, self-reported estimates of attendance rates were unable to be compared with actual attendance rates of participants. Ethnicity was collected as per the New Zealand Ministry of Health Ethnicity Data Protocols. ${ }^{22}$ 
Participants were asked to participate in a brief online survey about their experiences with Whānau Pakari. A multimodal strategy was used for both recruitment and response to allow for maximum recruitment into the study. Recruitment for the survey was by e-text with an invitation to participate in the confidential survey. The text contained a hyperlink to complete the survey online and the option to take the survey via phone or post. This was followed by 3 reminder texts over the following weeks. The capacity to "opt out" of the survey was also included. One invitation to participate was sent per family, so that families with more than 1 child involved in the service did not receive the invitation twice. Postal surveys were sent to the address provided by the participant, and telephone surveys were scheduled at a time convenient for the participant. Survey participants were offered the chance to win a voucher for sporting goods as an incentive to take the survey.

\section{Data Analysis}

Quantitative data were analyzed using SAS version 9.4 (SAS Institute, Cary, NC, 2016). Wilcoxon signed rank test and Spearman correlation coefficient were used because of the non-normal distribution of the data to compare the statement variables about the assessment and sessions between Māori and non-Māori and to assess the correlation with level of attendance. Logistic regression was used to assess the association of dichotomized attendance outcome variable with ethnicity and length of program. Qualitative data collected using open-text comment fields were coded and thematically analyzed in MAXQDA Standard 2018 (version 18.2.0, VERBI GmbH Software, Berlin, Germany, 2018). One researcher (CEKW) developed the coding matrix with training in development, application, and refinement from EJW and DMC, who have experience in both qualitative research and Indigenous health research. This was peer reviewed over several meetings with the wider research team for consistency within and between survey responses and to ensure overall rigor, $^{23}$ before CEKW coded the remainder of the dataset under supervision. Codes were amalgamated into related areas, which formed common themes present in the data.

The research team was comprised of both Indigenous Māori and nonMāori researchers. In the event of disagreement over the interpretation of the data concerning Māori participants, it was agreed to use the "Give Way" rule, whereby each researcher's contribution and standpoint are acknowledged, and the final decision involving cultural interpretation of Māori participants' experiences passes to a Mãori research team member. ${ }^{24}$

\section{RESULTS}

\section{Demographics}

A total of 344 potential respondents were asked to participate, of which 71 completed the survey, with a response rate of $21 \%(71 / 344)$, which is comparable to similar surveys of patient experience (Table 1). ${ }^{25,26}$ Ninety-two percent $(n=65)$ completed the survey online, $3 \%(n=2)$ completed by telephone, and $6 \%(n=4)$ completed by post; $45 \%$ identified as Māori, and $89 \%$ of respondents were female. Eighty-two percent $(n=58)$ were an accompanying adult (parents or caregivers) of a child involved in Whānau Pakari. Average time to complete the online survey was approximately 12 minutes. All respondents had accepted their referral to Whanau Pakari (ie, no families who were referred and declined further input responded to the survey).

Table 2 shows the level of agreement across a range of statements about the assessments and program sessions. Overall, the assessments and sessions were perceived to be convenient in terms of location and time. The program was perceived to be both appropriate and beneficial for families. There was more variation in the level of agreement with the statement, "Other things were more important at the time." Most participants agreed that the program was culturally appropriate.

Regarding attendance, self-reported higher attendance levels had a weak positive but significant association with respondents reporting the sessions to be conveniently located $\left(r_{\mathrm{s}}=0.29, P=.03\right)$. Attendance levels were lower when respondents reported other priorities to be more important for their family $\left(r_{\mathrm{s}}=-0.32, P=.02\right)$. Ethnicity was not associated with participant agreement with the statement, "I felt the program was culturally appropriate." However, Māori more frequently reported that past

Table 1. Sociodemographic and Input Level Data of Survey Respondents $(n=71)$

\section{Participants}

Accompanying adult as respondent

Child as respondent

Female

Ethnicity ${ }^{a}$

Accepted referral

Level of input

\section{Description}

Māori

32 (45)

$37(52)$

New Z
Asian

2 (3)

71 (100)

Home-based assessment and weekly sessions (high-intensity)

$39(55)$

Home-based assessment only (low-intensity)

$14(20)$

One assessment then decided not to be involved in the program

3 (4)

Started on home-based assessments only, then moved to weekly sessions 


\begin{tabular}{|c|c|c|c|c|c|}
\hline Statement & $\begin{array}{l}\text { Strongly } \\
\text { Agree }\end{array}$ & $\begin{array}{l}\text { Somewhat } \\
\text { Agree }\end{array}$ & $\begin{array}{l}\text { Neither Agree } \\
\text { nor Disagree }\end{array}$ & $\begin{array}{l}\text { Somewhat } \\
\text { Disagree }\end{array}$ & $\begin{array}{l}\text { Strongly } \\
\text { Disagree }\end{array}$ \\
\hline The assessments were in a convenient location. & $44(62)$ & $13(18)$ & $6(8)$ & $5(7)$ & $3(4)$ \\
\hline The assessments were at a convenient time. & $37(52)$ & $20(28)$ & $5(7)$ & $8(11)$ & $1(1)$ \\
\hline We had the time to attend assessments. & $34(48)$ & $23(32)$ & $8(11)$ & $6(8)$ & $0(0)$ \\
\hline The sessions were in a convenient location. & $24(44)$ & $17(32)$ & $6(11)$ & $6(11)$ & $1(2)$ \\
\hline The sessions were at a convenient time. & $23(43)$ & $18(33)$ & $5(9)$ & $8(15)$ & $0(0)$ \\
\hline We had the time to attend sessions. & $22(41)$ & $19(35)$ & $9(17)$ & $4(7)$ & $0(0)$ \\
\hline We had transportation to get to sessions. & $37(69)$ & $7(13)$ & $5(9)$ & $2(4)$ & $3(6)$ \\
\hline The program seemed appropriate for my family. & $30(56)$ & $15(28)$ & $4(7)$ & $4(7)$ & $1(2)$ \\
\hline I felt the program could work for my family. & $31(57)$ & $16(30)$ & $4(7)$ & $2(4)$ & $1(2)$ \\
\hline I felt my family would benefit from the program. & $33(61)$ & $16(30)$ & $3(6)$ & $2(4)$ & $0(0)$ \\
\hline $\begin{array}{l}\text { Other things were more important for my } \\
\text { family at the time. }\end{array}$ & $5(9)$ & $11(20)$ & $17(32)$ & $11(20)$ & $10(19)$ \\
\hline $\begin{array}{l}\text { Previous experiences with health care made } \\
\text { me not want my family to attend. }\end{array}$ & $1(2)$ & $8(15)$ & $10(19)$ & $8(15)$ & $27(50)$ \\
\hline $\begin{array}{l}\text { I thought other people might judge me and } \\
\text { my family for attending. }\end{array}$ & $5(9)$ & $8(15)$ & $8(15)$ & $9(17)$ & $24(44)$ \\
\hline I felt that the program was culturally appropriate. & $24(44)$ & $11(20)$ & $13(24)$ & $2(4)$ & $4(7)$ \\
\hline
\end{tabular}

a Statements concerning assessments were answered by $n=71$, and statements concerning sessions were answered by $n=54$, because of the survey's branching design.

Note: Data are presented as $\mathrm{n}(\%)$.

experiences of health care influenced their willingness to attend Whānau Pakari $(P=.03)$ (Wilcoxon signed rank test).

\section{Thematic Analysis of Barriers and Facilitators}

Thematic analysis of open-text comments highlighted 6 key themes that demonstrate the barriers and facilitators to engagement in the program experienced by participants (Table 3).

Facilitators identified included a concern for the child's or family's health, the perceived ease of accessibility of the program, and the ongoing support received once engaged in the program (Table 3). There was an indication that families are aware of the health issues and concerns and were looking for support, suggesting that this was an initial facilitator to attendance. Findings indicated that families did not believe they would achieve healthy lifestyle change on their own without support. The perceived accessibility of the service was identified as a facilitator of both the ability of the service to be convenient, accommodating and flexible, and the ability of the respondent to have access to personal resources to get to sessions, such as the availability of family support and transport. The ongoing support from the program received by participants, once they were involved in Whanau Pakari, was another facilitator to ongoing attendance. Key terms that respondents used were "non-judgmental," "encouraging," "supportive," "fun," and that the program built confidence and self-esteem.

Barriers identified included perceived suitability, perceived accessibility, and other priorities or activities (Table 3). The perceived suitability or appropriateness of the program for the child or family was a barrier for some respondents because of the wide age range of the children attending the program, from ages 5-16 years. For others, the program material was perceived to not be relevant for their family. In addition to being identified as a facilitator, the perceived accessibility of the program was also identified as a potential barrier to attendance. This likely reflected the need to travel to the weekly group sessions, rather than the home-based assessment aspect of the program. Lastly, respondents identified that attending Whānau
Pakari was not a priority over other activities or work.

\section{DISCUSSION}

In this study of New Zealand caregivers and participants referred to a community-based multidisciplinary assessment and intervention service for children and adolescents with obesity, the key findings were that concern for family health and the ongoing support provided by the team were key facilitators to initial and ongoing attendance. Perceived suitability of the program and the importance of other family priorities were found to be key barriers. Perceived accessibility of the program emerged as a key facilitator and barrier, depending on individual family circumstances. Second, although the program was considered culturally appropriate, past experiences of health care were reported to influence willingness to attend for Māori, but these experiences were not elaborated on in the qualitative comments.

Kelleher and colleagues ${ }^{10}$ identified personal and program logistics as barriers to initial and continued attendance. In this survey, the 
Table 3. Participant-Identified Barriers and Facilitators to Engagement in the Whanau Pakari Program From OpenText Comments

\begin{tabular}{|c|c|c|}
\hline Domain & Theme Identified & Example Feedback \\
\hline \multirow[t]{3}{*}{ Facilitators } & $\begin{array}{l}\text { Motivation to improve } \\
\text { health of child and/or } \\
\text { family }\end{array}$ & "We needed support and help and we could not do it on our own." (\#38) \\
\hline & Perceived accessibility & $\begin{array}{l}\text { "Based at home [...] no cost, petrol, don't have to find care for other } \\
\text { children, flexible." (\#77) }\end{array}$ \\
\hline & $\begin{array}{l}\text { Ongoing support from } \\
\text { program }\end{array}$ & $\begin{array}{l}\text { "The lady I spoke with each time was lovely, and spoke to you like a friend } \\
\text { and made you feel comfortable." (\#1) }\end{array}$ \\
\hline \multirow[t]{3}{*}{ Barriers } & Perceived suitability & $\begin{array}{l}\text { "Great program for those that need help with eating right food but we knew } \\
\text { and was doing all the stuff we was learning about so for me it was not } \\
\text { appropriate." (\#36) }\end{array}$ \\
\hline & Perceived accessibility & $\begin{array}{l}\text { "Had to stop attending as we ended up having no car to travel from [town] } \\
\text { to [town] each week." (\#7) }\end{array}$ \\
\hline & Other priorities/activities & $\begin{array}{l}\text { "I admit when we were getting worn out from all the busyness, it would be } \\
\text { Whannau Pakari that we chose not to go to." (\#15) }\end{array}$ \\
\hline
\end{tabular}

${ }^{a}$ Questions to elicit qualitative data included: (1) What were the factors that helped you attend Whanau Pakari sessions/assessments, if any? (2) What things prevented you from attending Whanau Pakari sessions/assessments, if any? (3) How could Whanau Pakari better meet your needs/the needs of your whānau/family? (4) Do you have any other comments about your experience with Whanau Pakari?

identification of program accessibility as both a facilitator and a barrier highlights the limitations of health care services in a fiscally-constrained environment to have capacity for program delivery in more locations around the region. Whereas the Whanau Pakari home-visit assessment model has removed the barrier of accessing a hospital appointment and overcome transport barriers, accessing weekly sessions is still highly dependent upon personal logistics such as service users having time and their own transportation. In addition, both the quantitative and qualitative data suggest that attendance is diminished when the program is considered a lower priority in comparison with other family activities or considerations, which is also reflected in the literature. $^{10}$

The strong agreement with the statement that the program was culturally appropriate is encouraging as Whanau Pakari endeavored to be more responsive and appropriate for Mãori participants than the previous model of care. However, Mãori respondents reported that past experiences of health care affected their willingness to attend Whanau Pakari. This suggests that further understanding of the relationship between past experiences of health care is required to understand how to improve engagement for Māori. While this has not been explored in the context of community-based healthy lifestyle programs, this finding has been explored in other areas of health care use, such as the association of negative health experiences with lower rates of cancer screening for Mãori women ${ }^{12}$ and the impact of past experiences on health care use among Aboriginal cardiac patients in Australia. ${ }^{27}$

The findings of this study were generally consistent with a previous systematic review of barriers and facilitators to initial and continued attendance in community-based lifestyle programs, which showed that parental concern for child health and wellbeing was a driving factor to attendance, and over time, positive program experiences fostered continued attendance. ${ }^{10}$ In this survey, the collection of open-text comments alongside the quantitative data provided valuable insight into participant experiences, and the ongoing support received from the program deliverers was identified by respondents as a facilitator of ongoing engagement. The New Zealand Health Survey highlighted that Mãori and those from the most deprived levels of household deprivation experience the greatest levels unmet need owing to cost or transportation. ${ }^{3}$ Given these groups are over-represented in child obesity statistics, the continuity of care provided by a multidisciplinary team undertaking an assessment and intervention is likely to favorably address equity in this area.

A strength of the study was the wide representation by ethnicity with $45 \%$ of respondents identifying as Marori. This is comparable to the recruitment rate in the Whanau Pakari randomized clinical trial ${ }^{16}$ and higher than the background rate of Māori in Taranaki, which is $19 \% .^{18}$ Limitations included the unavoidable level of sample bias due in part to response rate, which may have affected validity, and the potential recall bias for some participants whose time period between program participation and survey response was up to 5 years. This study tried to attain the greatest response rate possible by offering multiple modes for responses and sending 2 weekly or fortnightly reminder texts during the study. Despite the low response rate, there was good representation from Indigenous respondents, which suggests that the findings are still useful. ${ }^{28}$ This study also included respondents who had the option to be involved in a 6-month or 12month program, the latter of which had 2 more opportunities for contact via assessments, which may 
have resulted in differences in program experience. However, this survey is a representation of the realworld experience of a clinical service of this nature, which is why it was opted to include this group within the study.

\section{IMPLICATIONS FOR RESEARCH AND PRACTICE}

Given that only participants who had accepted their referral responded to the survey, there is a need to determine the barriers to initial engagement for the group who declined further contact with the service after being referred. In-depth interviews are underway to understand the barriers for this group and the relationship between past experiences with health care and subsequent engagement with services such as Whānau Pakari, particularly for Māori. It is hoped that understanding the barriers and facilitators to engagement in Whānau Pakari can contribute toward the improvement of prevailing health care models and help work toward health equity.

\section{ACKNOWLEDGMENTS}

This work was supported by the National Science Challenge A Better Start and Cure Kids. The funders of the study had no role in the study design, data collection, data analysis, data interpretation, or writing of the report.

The authors thank the participants of Whānau Pakari. We also thank the Taranaki District Health Board and Sport Taranaki for support of the trial.

\section{SUPPLEMENTARY DATA}

Supplementary data related to this article can be found at https://doi. org/10.1016/j.jneb.2019.10.010.

\section{REFERENCES}

1. World Health Organization. Report of the Commission on Ending Childhood Obesity. Geneva, Switzerland: World Health Organization; 2016.
2. New Zealand Ministry of Health. Childhood Obesity Plan. Wellington, New Zealand: New Zealand Ministry of Health; 2015

3. New Zealand Ministry of Health. Tier 1 statistics 2016/17: New Zealand Health Survey. Wellington, New Zealand: New Zealand Ministry of Health; 2017.

4. Anderson YC, Wynter LE, Treves KF, et al. Assessment of health-related quality of life and psychological wellbeing of children and adolescents with obesity enrolled in a New Zealand community-based intervention programme: an observational study. $B M J$ Open. 2017;7:e015776.

5. Anderson YC, Wynter LE, Butler MS, et al. Dietary intake and eating behaviours of obese New Zealand children and adolescents enrolled in a community-based intervention programme. PLOS One. 2016;11:e166996.

6. Anderson YC, Wynter LE, Grant CC, et al. Physical activity is low in obese New Zealand children and adolescents. Sci Rep. 2017;7:41822.

7. Anderson YC, Wynter LE, Treves KF, et al. Prevalence of comorbidities in obese New Zealand children and adolescents at enrolment in a communitybased obesity programme. I Paediatr Child Health. 2016;52:1099-1105.

8. Skelton JA, Beech BM. Attrition in paediatric weight management: a review of the literature and new directions. Obes Rev Off J Int Assoc Study Obes. 2011;12:e273-e281.

9. Ligthart KAM, Buitendijk L, Koes BW, van Middelkoop $M$. The association between ethnicity, socioeconomic status and compliance to pediatric weightmanagement interventions - a systematic review. Obes Res Clin Pract. 2017;11: $1-51$.

10. Kelleher E, Davoren MP, Harrington JM, Shiely F, Perry IJ, McHugh SM. Barriers and facilitators to initial and continued attendance at community-based lifestyle programmes among families of overweight and obese children: a systematic review. Obes Rev. 2017;18:183-194.

11. Perry RA, Daniels LA, Bell L, Magarey AM. Facilitators and barriers to the achievement of healthy lifestyle goals: qualitative findings from Australian parents enrolled in the PEACH child weight management program. J Nutr Educ Behav. 2017;49:43-52.
12. Harris R, Cormack D, Tobias M, et al. Self-reported experience of racial discrimination and health care use in New Zealand: results from the 2006/7 New Zealand Health Survey. Am J Public Health. 2012;102:1012-1019.

13. Zambas SI, Wright J. Impact of colonialism on Māori and aboriginal healthcare access: a discussion paper. Contemp Nurse. 2016;52:398-409

14. Anderson YC, Wynter LE, Moller $\mathrm{KR}$, et al. The effect of a multidisciplinary obesity intervention compared to usual practice in those ready to make lifestyle changes: design and rationale of Whanau Pakari. BMC Obes. 2015;2:41.

15. Kalarchian MA, Levine MD, Arslanian SA, et al. Family-based treatment of severe pediatric obesity: randomized, controlled trial. Pediatrics. 2009;124: 1060-1068.

16. Anderson Y, Wynter L, Grant C, et al. A novel home-based intervention for child and adolescent obesity: the results of the Whānau Pakari randomized controlled trial. Obesity. 2017;25:1965-1973.

17. Cole TJ. A chart to link child centiles of body mass index, weight and height. Eur J Clin Nutr. 2002;56: 1194-1199

18. New Zealand Ministry of Health. Population of Taranaki DHB. Wellington, New Zealand: New Zealand Ministry of Health; 2019. https://www.health. govt.nz/new-zealand-health-system/ my-dhb/taranaki-dhb/population-taranaki-dhb. Accessed November 11, 2019.

19. Pihama L. Kaupapa Māori theory: transforming theory in Aotearoa. He Pukenga Korero. 2010;9:5-14.

20. Smith LT. Decolonizing Methodologies: Research and Indigenous Peoples. London, UK: Zed Books; 1999.

21. Krieger N. Methods for the scientific study of discrimination and health: an ecosocial approach. Am J Public Health. 2012;102:936-944

22. New Zealand Ministry of Health. HISO 10001:2017 Ethnicity Data Protocols. Wellington, New Zealand: New Zealand Ministry of Health; 2017.

23. Chilisa B. Indigenous Research Methodologies. Thousand Oaks, CA: SAGE Publications, Inc; 2011

24. Curtis ET, Wikaire E, Lualua-Aati T, et al. Tátou Tátou/Success for All: Improving Māori Student Success. Wellington, New Zealand: Ako Aotearoa National 
Centre for Tertiary Teaching Excellence; 2012.

25. Health Quality and Safety Commission New Zealand. Patient experience survey: results for patients treated in February 2018. Wellington, New Zealand: Health Quality and Safety Commission New Zealand; 2018.
26. Safdar N, Abbo LM, Knobloch MJ, Seo SK. Research methods in healthcare epidemiology: survey and qualitative research. Infect Control Hosp Epidemiol. 2016;37:1272-1277.

27. Artuso S, Cargo M, Brown A, Daniel M. Factors influencing health care utilisation among Aboriginal cardiac patients in central Australia: a qualitative study. BMC Health Serv Res. 2013; 13:83.

28. Morton SM, Bandara DK, Robinson EM, Carr PE. In the 21st century, what is an acceptable response rate? Aust N Z J Public Health. 2012; 36:106-108.

\section{Need Help Remembering?}

Sign up for JNEB alerts and never worry about checking for the new JNEB issues or relevant research again!

JNEB offers 3 automatic alerts:

- free access to Tables of Contents and all article abstracts

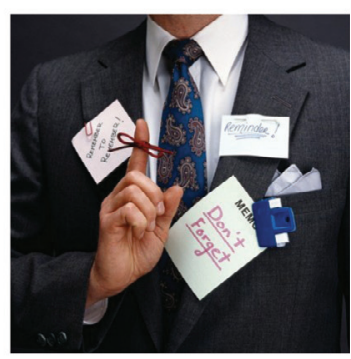

- free access to select full text articles

- free e-alerts and search personalization

To register for alerts, go to: http://www.jneb.org/user/alerts 